\title{
Study on antipyretic activity of Rumex vesicarius leaves extract in albino rabbits
}

\author{
Imran Ahmad Khan ${ }^{1}$, Abdul Aziz' ${ }^{1}$ Zahid Manzoor², Shaukat Hussain Munawar², Hafiz Shoaib Sarwar ${ }^{1}$,
} Aqsa Afzal ${ }^{1}$ and Muhammad Asif Raza ${ }^{3}$

\begin{abstract}
1. Faculty of Pharmacy, Bahauddin Zakariya University, Multan, Pakistan; 2. Department of Pharmacology, Faculty of Medicine and Allied Medical Sciences, Al-Nafees Medical College, I sra University, Islamabad, Pakistan; 3. Department of Animal Husbandry in tropics and sub tropics, University of Kassel, Germany Corresponding author: Zahid Manzoor, email: dr_hafizzahid@hotmail.com

Received: 14-11-2013, Revised: 11-12-2013, Accepted: 17-12-2013, Published online: 31-01-2014
\end{abstract}

doi: 10.14202 /vetworld.2014.44-48

How to cite this article: Khan IA, Abdul Aziz, Zahid Manzoor, Munawar SH, Sarwar HS, Aqsa Afzal and Raza MA (2014) Study on antipyretic activity of Rumex vesicarius leaves extract in albino rabbits, Veterinary World 7(1): 44-48.

\begin{abstract}
Aim: The present study was planned to investigate the possible antipyretic activity of methanolic leaves extract of Rumex vesicarius against various protocols of experimentally induced pyrexia in rabbits.

Materials and Methods: Ninety healthy adult albino rabbits were divided into three groups (A, B, C), 30 rabbits in each group. Pyrexia was induced by three different protocols, i.e. boiled milk $(0.5 \mathrm{ml} / \mathrm{kg}$ body weight, intra-peritonealy), Brewer's yeast $(10 \mathrm{ml} / \mathrm{kg}$, subcutenously) and D-amphetamine $(5 \mathrm{mg} / \mathrm{kg}$, i.p.), to the groups A, B and C respectively. Each group was further subdivided into five sub groups (1,2,3, 4 and 5) each having 6 animals. Sub group-1 served as positive control group; sub group- 2 was treated with aspirin $(10 \mathrm{mg} / \mathrm{kg}$, orally) standard antipyretic agent; sub group-3, 4 and 5 were treated orally with methanolic leaves extract of Rumex vesicarius at dose rate of 80,120 and $160 \mathrm{mg} / \mathrm{kg}$ body weight respectively. The hypothermic effect was observed at different time intervals in each protocol.
\end{abstract}

Results: Rumex vesicarius L. significantly $(\mathrm{p}<0.05)$ lowered the elevated temperature in all scenarios. Maximum antipyretic effect was observed at $3 \mathrm{~h}$ of post induction pyrexia in group A and at $4 \mathrm{~h}$ after pyrexia in the groups B and C. Moreover, the antipyretic effect was concentration dependent and comparable to the standard aspirin at higher doses.

Conclusion: The leaves of Rumex vesicarius have the antipyretic action in dose dependent manner, based upon this scientific validation, the claims of the local communities are true. The exact mode of action of this plant is still not clear, however, a single or a number of bioactive compounds of the plant may be responsible for its antipyretic activity.

Keywords: aspirin, D-amphetamine, pyrexia, rabbits, Rumex vesicarius (L.).

\section{Introduction}

Over the centuries, medicinal plants served as a tremendous remedy for a variety of ailments in mankind worldwide [1]. Primarily, these plants are used as a vital source of health care system [2]. In Pakistan, this trend is well-known in the name of Hikmat/Tabib. Approximately 600-1000 medicinal plants of the country are being utilized by more than 40,000 registered and unregistered Hakims or Tabib [3]. This practice is derived from experiences, without any scientific evidence; thus a proper validation of scientific grounds is necessary [4].

Pyrexia or fever occurred as a result of secondary impact of infection, malignancy or other diseased states [5]. It creates naturally such an environment in the body where infectious agents or damaged tissues cannot survive [5]. In general, the infected or damaged tissue stimulates the rapid formation of proinflammatory mediators (cytokines, such as interleukin $1 \beta, \alpha, \beta$, and TNF- $\alpha$ ), sequentially enhancing the synthesis of prostaglandin E2 (PgE2) near hypothalamic area and thereby trigerring the hypothalamus to elevate the body

Copyright: The authors. This article is an open access article licensed under the terms of the Creative Commons Attribution License (http://creativecommons.org/licenses/by/2.0) which permits unrestricted use, distribution and reproduction in any medium, provided the work is properly cited. temperature [6]. Antipyretic drugs usually inhibit COX-2 expression to decrease the elevated body temperature by inhibiting PgE2 biosynthesis [7]. These synthetic agents irreversibly inhibit COX-2 with high selectivity but toxic to cardiac muscles, hepatic cells, glomeruli, and cortex of brain. On the other hand, natural COX-2 inhibitors have lower selectivity with few side effects [7]. Search for herbal remedies with potent antipyretic activity received momentum recently as the available antipyretics, such as paracetamol, nimusulide etc. have toxic effects on the various organs of the body.

Rumex vesicarius $\mathrm{L}$. is an annual plant belong to family Polygonaceae, commonly known as "Bladder dock" and locally as "Khat palak" [8]. $R$. vesicarius $(\mathrm{RvCr})$ is widely distributed throughout Pakistan, India, Bangladesh, America, and North Africa. In Pakistan, it is available in the districts of south Punjab. The plant is widely cultivated as a vegetable in Tripura, Bihar, West Bengal, Andhra Pradesh and Muzaffar Garh. The folk use of this plant is laxative, appetizer, diuretic, analgesic, purgative, stomachic, astringent, antispasmodic and antibacterial [8]. In addition, it has been used in the treatment of tumors, piles, calcules, bad digestion, nausea, dyspepsia, flatulence, constipation, heart troubles, pains, diseases of the spleen, hiccough, 
asthma, bronchitis, scabies, leucoderma, toothache and hepatic diseases [8]. The leaves are applied externally to burns while the seeds are tonic, remove pain from the back and the lumber region and aphrodisiac [9]. The methanol extract of the roots has antidiarrhoeal [10], antimotility, and neuropharmacological activities. The medicinal importance of this plant is a reflection to its chemical composition as the plant has many bioactive substances [11].

In Pakistan, local Tabibs/Hakims claim the antipyretic effects of Rumex vesicarius leaves and are being used this plant as antipyretic agent without any reported scientific evidence. Therefore, this study has been planned to evaluate the possible antipyretic activity of Rumex vesicarius if any; and to validate the claims of local Tabibs/Hakims.

\section{Materials and Methods}

Ethical approval: The protocol of the study was approved by the College Ethical Committee (ECE) according to the guidelines provided by the ECE for the Control and Supervision of Experiments on Animals (CSEA).

Plant material: Leaves of the plant were collected from various part of Mondka Shahlamal District Muzaffar Garh, Pakitan with the help of a local herbalist and identified by Prof. Dr. Altaf Dasti, Institute of Pure and Applied Biology, Bahauddin Zakariya University, Multan, Pakistan, where its voucher specimen (No. FPST215) was deposited. The leaves were air-dried and ground into powder.

Preparation of crude extract: The powdered plant material $(1 \mathrm{~kg})$ was subjected to maceration in $70 \%$ methanol in amber colored glass bottle at room temperature for 8 days with occasional shaking [12]. The solution was filtered through muslin cloth and Whattma-1 filter paper to remove any undesirable material. The filtrate was evaporated on a rotary evaporator (Rotavapor, BUCHI labrotechnik AG, Model 9230, Switzerland) at $37^{\circ} \mathrm{C}$ under reduced pressure and the extract was stored at $-4^{\circ} \mathrm{C}$ in air tight jars in lab refrigerator.

Chemical reagents: D-amphetamine (BSA conjugant, Shanghai Jieyi Biotechnology Co., Ltd.), Brewer's yeast (Jinan Shuangmai Beer Materials Co., Ltd.) were procured from local market and $20 \% \mathrm{~W} / \mathrm{V}$ suspension of yeast was prepared. Aspirin as Disprin soluble tablet was purchased from a local market of Reckitt Benckiser (Paksitan) Ltd and used as an antipyretic agent. The standard solution was prepared by dissolving the tablet in the solvent to obtain $15 \mathrm{mg}$ aspirin per $2 \mathrm{ml}$ solution. The dose of aspirin was maintained at $10 \mathrm{mg} / \mathrm{kg}$ body weight [13].

Animals: The experiment was carried out on albino rabbits of both sexes, 13-15 months old, weighing between 1.5 and $1.6 \mathrm{~kg}$ [14] at the laboratory of AlManara College of Pharmacy, Multan. Animals were purchased from the local market of Multan. Prior to the experiment, the rabbits were kept in iron cages [15] to become accustomed to the environment, and fed with cauliflower, cabbage, banana, and tap water for 40 days. Food and water were withdrawn $6 \mathrm{~h}$ earlier to the start of experiment [13].

Acute toxicity study: Acute toxicity study was performed by graded doses (50 to $500 \mathrm{mg} / \mathrm{kg}$ ) of methanolic extract of $R$. vesicarius intraperitonealy. The animals were observed critically for the first $2 \mathrm{~h}$ of post administration, for any toxic symptoms and up to $24 \mathrm{~h}$ for any mortality [16].

Treatment protocol: Prior to the experiment, the rectal temperatures of the rabbits were recorded by inserting a well lubricated bulb of a thermometer into the rectum carefully [13]. A total of 90 albino rabbits were divided into three groups $\mathrm{A}, \mathrm{B}$ and $\mathrm{C}$, each with 30 animals. Pyrexia was induced by following three different protocols to these groups.

a. Milk-induced pyrexia: Milk was collected from local cattle. Rabbits of group-A were injected with boiled milk intra-peritonealy at room temperature at the dose of $0.5 \mathrm{ml} / \mathrm{kg}$ body weight to induce pyrexia. Fever occurred about 1 to $2 \mathrm{~h}$ post administration [13, 17]. Rabbits were divided into five sub-groups (1 to 5), 6 rabbits in each sub-group. Sub-group-1 served as positive control group whereas sub-group-2 received the known antipyretic agent aspirin at dose rate of (10 $\mathrm{mg} / \mathrm{kg}$ orally) and served as negative control group. Sub-groups 3, 4 and 5 received methanolic extract of $R$. vesicarius orally at dose rate of $80 \mathrm{mg}, 120 \mathrm{mg}$ and 160 $\mathrm{mg} / \mathrm{kg}$ respectively. Finally, rectal temperatures were recorded at $1 \mathrm{~h}$ intervals up to $3 \mathrm{~h}$.

b. Yeast-induced pyrexia: Each rabbit of group-B was administered subcutaneously with $20 \% \mathrm{~W} / \mathrm{V}$ aqueous suspension of yeast at a volume of $10 \mathrm{ml} / \mathrm{kg}$ [18], animals with elevated temperatures upto $1^{\circ} \mathrm{C}$ were preferred for the study. The arrangements of rabbits of group-B into sub-groups were similar to the group-A. The extract understudy was administered orally after the pyrogen at the dose of $80 \mathrm{mg} / \mathrm{kg}, 120 \mathrm{mg} / \mathrm{kg}$, and $160 \mathrm{mg} / \mathrm{kg}$ to respective groups of rabbits. The control group received distilled water $(10 \mathrm{ml} / \mathrm{kg})$ whereas aspirin was administered to the reference group. The rectal temperature of the groups were recorded at $1 \mathrm{~h}$ interval for $5 \mathrm{~h}$.

c. D-amphetamine induced pyrexia: Amphetamine (5 $\mathrm{mg} / \mathrm{kg}$, i.p.) was administered to the rabbits of group-C after obtaining basal temperatures. Hyperthermia developed $0.5 \mathrm{~h}$ following administration. Rabbits were placed into sub-groups on similar pattern as group-A and B. The extract (80, 120 and $160 \mathrm{mg} / \mathrm{kg}$, orally), aspirin (10 mg/kg orally) were administered to the animals at peak hyperthermia. Rectal temperature was obtained at $1 \mathrm{~h}$ interval for $5 \mathrm{~h} \mathrm{[18]}$.

Determination of percent pyrexia inhibition: The 
Boiled milk-induced pyrexia

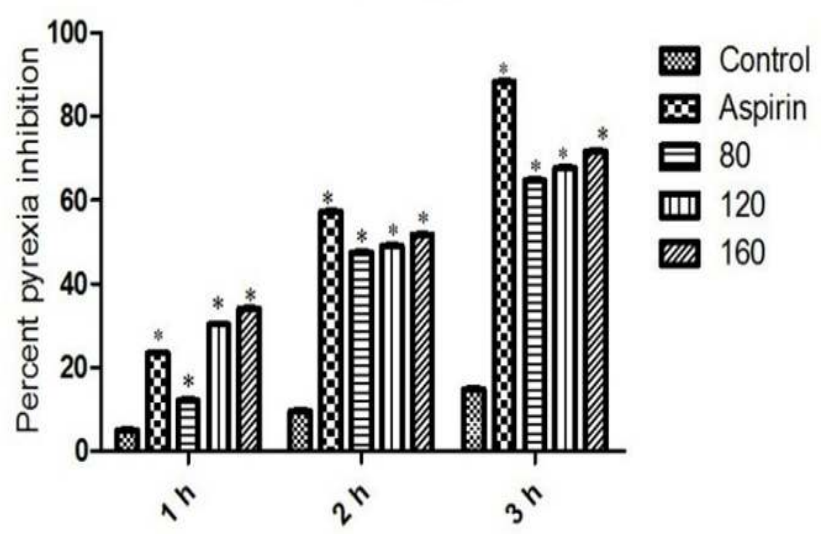

Figure-1. Antipyretic effect of Rumex vesicarius in rabbits. Bar represents the percent inhibition of pyrexia (boiled milk induced) after 1,2 and $3 \mathrm{~h}$ of the treatment with aspirin $(10 \mathrm{mg} / \mathrm{kg})$ and Rv. Cr. $(80-160 \mathrm{mg} / \mathrm{kg})$. Asterisks indicates statistically significant values from control. * $\mathrm{P}<0.05$

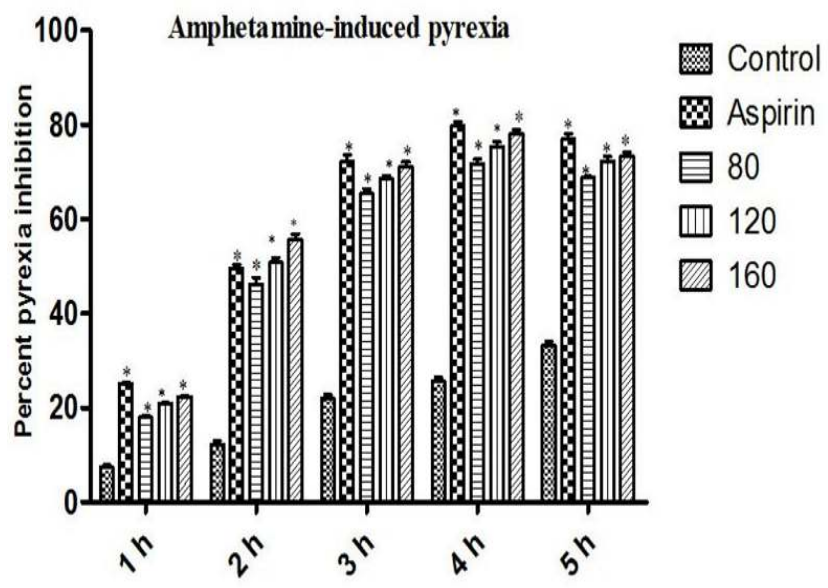

Figure-3. Antipyretic effect of Rumex vesicarius in rabbits. Bar represents the percent inhibition of pyrexia (amphetamine induced) after $1,2,3,4$ and $5 \mathrm{~h}$ of the treatment with aspirin $(10 \mathrm{mg} / \mathrm{kg})$ and Rv.Cr. $(80-160 \mathrm{mg} / \mathrm{kg})$. Asterisks indicates statistically significant values from control. * $\mathrm{P}<0.05$

percent pyrexia inhibition was calculated by the following formula:

Percentage reduction $=\mathrm{B}-\mathrm{Cn} / \mathrm{B}-\mathrm{A} X 100$

Where $\mathrm{n}=1,2,3,4$ and 5

Statistical analysis: Data generated in the present study were subjected to statistical analysis by paired student's $\mathrm{t}$ - test for calculation and comparison of mean values between the groups at various intervals. A level of significance was based on the $95 \%$ level of probability. The results were expressed as mean \pm standard error (SEM).

\section{Results}

Phytochemical screening: The phytochemical screening of the methanolic extract of the whole plant of Rumex vesicarius revealed the presence of saponins, tannins, anthraquinones, coumarins, phenols and flavanoid (Table-1).

Acute toxicity: In acute toxicity study, $\mathrm{RvCr}$ was found safe at all test doses and no mortality was observed to a dose as high as $500 \mathrm{mg} / \mathrm{kg}$.

\section{Yeast-induced pyrexia}

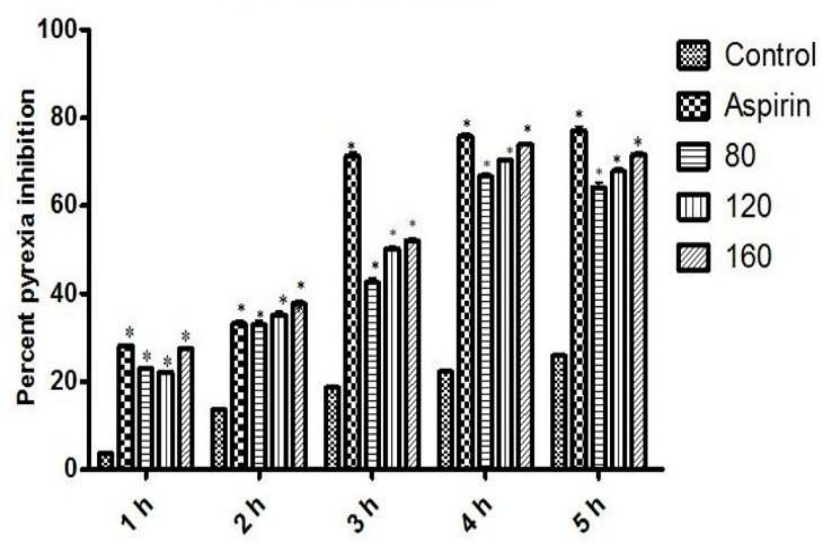

Figure-2. Antipyretic effect of Rumex vesicarius in rabbits. Bar represents the percent inhibition of pyrexia (yeast induced) after 1 , $2,3,4$ and $5 \mathrm{~h}$ of the treatment with aspirin $(10 \mathrm{mg} / \mathrm{kg})$ and Rv.Cr. $(80-160 \mathrm{mg} / \mathrm{kg})$. Asterisks indicates statistically significant values from control. * $\mathrm{P}<0.05$

Table-1. Phytochemical screening of methanolic extract of whole plant of Rumex vesicarius

\begin{tabular}{llll}
\hline Sr. No. & Test & Observations & Result \\
\hline 1 & Alkaloid & No ppt & Negative \\
2 & Saponins & 1cm froth & Positive \\
3 & Tannins & Light purple & Positive \\
4 & Anthraquinones & Pink & Positive \\
5 & Coumarins & Yellow fluorescence & Positive \\
6 & Phenols & Light purple & Positive \\
7 & Flavanoid & Light yellow colour & Positive \\
\hline
\end{tabular}

Effect on boiled milk-induced pyrexia: The resultant effects of various doses of Rumex vesicarius leaves on boiled milk induced pyrexia in rabbits are depicted in Table-2. The RvCr markedly $(\mathrm{P}<0.05)$ attenuated hyperthermia induced by boiled milk. The percent pyrexia inhibition was dose dependent and remained significant up to $3 \mathrm{~h}$ of administration (Figure-1). The maximum antipyretic effect was observed at 160 $\mathrm{mg} / \mathrm{kg}$ i.e. $71 \%$ while the antipyretic effect of aspirin was $88 \%$ after $3 \mathrm{~h}$ of induction of hyperthermia.

Effect on yeast-induced pyrexia: The results revealed the antipyretic effects in a dose dependent manner, at all test doses (80, 120 and $160 \mathrm{mg} / \mathrm{kg}$ orally) as shown in Table-3. The percent pyrexia inhibition is presented in Figure-2. Maximum antipyretic effect (74\%) was observed at $160 \mathrm{mg} / \mathrm{kg}$ dose of $\mathrm{RvCr}$ after $4 \mathrm{~h}$ of induction of pyrexia. The antipyretic activity of aspirin $(77.14 \%)$ was greater than that of the highest dose of $\mathrm{RvCr}$.

Effect on amphetamine-induced pyrexia: The results revealed the antipyretic activity of all the test doses $(80$, 120 and $160 \mathrm{mg} / \mathrm{kg}$ orally) of $\mathrm{RvCr}$ as shown in 
Table-2. Effect of methanolic extract of Rumex vesicarius leaves on boiled milk-induced pyrexia in rabbits

\begin{tabular}{|c|c|c|c|c|c|c|}
\hline \multirow[t]{2}{*}{ Treatment } & \multirow[t]{2}{*}{ Dose (mg/kg) } & \multicolumn{2}{|c|}{ Rectal temperature $\left({ }^{\circ} \mathrm{C}\right)$} & \multicolumn{3}{|c|}{ Rectal temperature after treatment $\left({ }^{\circ} \mathrm{C}\right)$} \\
\hline & & Normal(A) & $\begin{array}{l}3 \mathrm{~h} \text { after boiled } \\
\text { milk admin. (B) }\end{array}$ & $1 \mathrm{~h} \mathrm{(C1)}$ & $2 \mathrm{~h}(\mathrm{C} 2)$ & $3 \mathrm{~h} \mathrm{(C3)}$ \\
\hline $\begin{array}{l}\text { Control } \\
\text { Aspirin } \\
\text { Rv.Cr. } \\
\text { Rv.Cr. } \\
\text { Rv.Cr. }\end{array}$ & $\begin{array}{l}10 \\
80 \\
120 \\
160\end{array}$ & $\begin{array}{l}38.42 \pm 0.35 \\
38.67 \pm 0.27 \\
38.52 \pm 0.29 \\
38.61 \pm 0.12 \\
38.64 \pm 0.18\end{array}$ & $\begin{array}{l}40.18 \pm 0.24 \\
40.12 \pm 0.16 \\
40.08 \pm 0.21 \\
40.16 \pm 0.24 \\
40.05 \pm 0.26\end{array}$ & $\begin{array}{l}40.09 \pm 0.17 \\
39.78 \pm 0.24 \\
39.89 \pm 0.37 \\
39.69 \pm 0.28 \\
39.57 \pm 0.12\end{array}$ & $\begin{array}{l}40.01 \pm 0.26 \\
39.29 \pm 0.32 \\
39.34 \pm 0.34 \\
39.40 \pm 0.37 \\
39.32 \pm 0.32\end{array}$ & $\begin{array}{l}39.92 \pm 0.09 \\
38.84 \pm 0.21 \\
39.07 \pm 0.28 \\
39.11 \pm 0.42 \\
39.04 \pm 0.14\end{array}$ \\
\hline
\end{tabular}

Table-3. Effect of methanolic extract of Rumex vesicarius leaves on yeast induced-pyrexia in rabbits

\begin{tabular}{|c|c|c|c|c|c|c|c|c|}
\hline \multirow[t]{2}{*}{ Treatment } & \multirow[t]{2}{*}{ Dose (mg/kg) } & \multicolumn{2}{|c|}{ Rectal temperature $\left({ }^{\circ} \mathrm{C}\right)$} & \multicolumn{5}{|c|}{ Rectal temperature after treatment $\left({ }^{\circ} \mathrm{C}\right)$} \\
\hline & & Normal(A) & $\begin{array}{l}3 \mathrm{~h} \text { after boiled } \\
\text { milk admin. (B) }\end{array}$ & $1 \mathrm{~h}(\mathrm{C} 1)$ & $2 \mathrm{~h}(\mathrm{C} 2)$ & $3 \mathrm{~h}(\mathrm{C} 3)$ & $4 \mathrm{~h}(\mathrm{C} 4)$ & $5 \mathrm{~h}(\mathrm{C} 3)$ \\
\hline & - & $38.78 \pm 0.08$ & $40.98 \pm 0.25$ & $40.90 \pm 0.09$ & $40.68 \pm 0.15$ & $40.57 \pm 0.21$ & $40.49 \pm 0.19$ & $40.41 \pm 0.24$ \\
\hline Aspirin & 10 & $38.38 \pm 0.09$ & $40.61 \pm 0.19$ & $39.98 \pm 0.12$ & $39.87 \pm 0.13$ & $39.02 \pm 0.35$ & $38.92 \pm 0.14$ & $38.89 \pm 0.38$ \\
\hline Rv.Cr. & 80 & $38.27 \pm 0.12$ & $40.67 \pm 0.24$ & $40.12 \pm 0.26$ & $39.88 \pm 0.27$ & $39.65 \pm 0.28$ & $39.07 \pm 0.22$ & $39.13 \pm 0.21$ \\
\hline Rv.Cr. & 120 & $38.45 \pm 0.07$ & $40.44 \pm 0.27$ & $40.00 \pm 0.08$ & $39.74 \pm 0.31$ & $39.44 \pm 0.16$ & $39.04 \pm 0.29$ & $39.09 \pm 0.19$ \\
\hline Rv.Cr. & 160 & $38.38 \pm 0.14$ & $40.53 \pm 0.09$ & $39.94 \pm 0.18$ & $39.72 \pm 0.07$ & $39.41 \pm 0.08$ & $38.94 \pm 0.32$ & $38.99 \pm 0.35$ \\
\hline
\end{tabular}

Table-4. Effect of methanolic extract of Rumex vesicarius leaves on yeast induced-pyrexia in rabbits

\begin{tabular}{|c|c|c|c|c|c|c|c|c|}
\hline \multirow[t]{2}{*}{ Treatment } & \multirow[t]{2}{*}{ Dose (mg/kg) } & \multicolumn{2}{|c|}{ Rectal temperature $\left({ }^{\circ} \mathrm{C}\right)$} & \multicolumn{5}{|c|}{ Rectal temperature after treatment $\left({ }^{\circ} \mathrm{C}\right)$} \\
\hline & & Normal(A) & $\begin{array}{l}3 \mathrm{~h} \text { after boiled } \\
\text { milk admin. (B) }\end{array}$ & $1 \mathrm{~h}(\mathrm{C} 1)$ & $2 \mathrm{~h}(\mathrm{C} 2)$ & $3 \mathrm{~h}(\mathrm{C} 3)$ & $4 \mathrm{~h}(\mathrm{C} 4)$ & $5 \mathrm{~h}(\mathrm{C} 3)$ \\
\hline Control & & $38.18 \pm 0.35$ & $40.87 \pm 0.14$ & $40.67 \pm 0.19$ & $40.54 \pm 0.26$ & $40.28 \pm 0.31$ & $40.18 \pm 0.24$ & $39.98 \pm 0.27$ \\
\hline Aspirin & 10 & $38.26 \pm 0.28$ & $40.64 \pm 0.18$ & $40.04 \pm 0.27$ & $39.46 \pm 0.34$ & $38.92 \pm 0.29$ & $38.74 \pm 0.14$ & $38.81 \pm 0.16$ \\
\hline Rv.Cr. & 80 & $38.38 \pm 0.11$ & $40.72 \pm 0.22$ & $40.30 \pm 0.34$ & $39.64 \pm 0.29$ & $39.19 \pm 0.17$ & $39.04 \pm 0.18$ & $39.11 \pm 0.26$ \\
\hline Rv.Cr. & 120 & $38.64 \pm 0.16$ & $40.55 \pm 0.29$ & $40.15 \pm 0.12$ & $39.58 \pm 0.18$ & $39.24 \pm 0.13$ & $39.11 \pm 0.22$ & $39.17 \pm 0.15$ \\
\hline Rv.Cr. & 160 & $38.21 \pm 0.24$ & $40.49 \pm 0.13$ & $39.98 \pm 0.15$ & $39.22 \pm 0.24$ & $38.87 \pm 0.19$ & $38.71 \pm 0.28$ & $38.82 \pm 0.31$ \\
\hline
\end{tabular}

Table-4. The percent pyrexia inhibition is presented in Figure-3. There was a progressive dose-dependent reduction in amphetamine-induced hyperthermia. The maximum antipyretic effect $(78 \%)$ was exhibited at dose of $160 \mathrm{mg} / \mathrm{kg}$ of $\mathrm{RvCr}$ on $4^{\text {th }} \mathrm{hr}$ post induction of pyrexia. The antipyretic effect of aspirin $(80 \%)$ was lowered than the highest dose of $\mathrm{RvCr}$.

\section{Discussion}

The acute toxicity study result showed that this plant might be considered a broad nontoxic one. Our experimental results revealed that all the three different doses $(80,120$ and $160 \mathrm{mg} / \mathrm{kg}$ ) of Rumex vesicarius $\mathrm{L}$. possess a significant antipyretic effect in maintaining normal body temperature and reduce all the three different protocols of elevated rectal temperature in rabbits. Moreover, the antipyretic action of the plant is comparable to that of the standard antipyretic drug, aspirin. Such reduction of rectal temperature of the tested animals by the various doses of $\mathrm{RvCr}$ is possibly because of the presence of a single bioactive substance or a mixture of compounds in them.

In this study, the methanolic extract of Rumex vesicarius was found to inhibit drastically $(\mathrm{P}<0.05)$ the boiled milk, D-amphetamine and yeast induced pyrexia in dose dependant manner. These all compounds have different mechanism of action to induce pyrexia. Amphetamine triggers the release of biogenic amines from their storage sites in nerve terminals resulting in high level of cAMP in brain. This leads to the synthesis of prostaglandins from arachidonic acids produced in neurons by receptor-mediated hydrolysis of phospho- lipids that ultimately results in hyperthermia [19]. Yeast has a different mechanism of action and served as a model for pathogenic fever. Yeast stimulates the release of inflammatory mediators like cytokines - IL1 , IL-6, TNF etc., leading to hyperthermia. Prostaglandins E2 produced by cyclooxygenase (COX-2) is regarded as an imperative downstream mediator of fever within the hypothalamus [7]. Most of the non-steroidal antiinflammatory drugs evoke their antipyretic action through the inhibition of prostaglandin synthetase within the hypothalamus. The antipyretic action is possibly due to a decrease in the brain concentration of prostaglandin E2 especially in the hypothalamus through its action on COX-2 or by enhancement of the production of the body's own antipyretic substances like vasopressin and arginine [20]. The other possible mechanism is that the extract could have mediated the dilation of superficial blood vessels which in turn leads to improved dissipation of heat following resetting of hypothalamic temperature control center [21]. This action may be account of phytochemical compounds present in the plant. Therefore, the hypothermic activity of the extract may not be disparate with the inhibition of one or combination of the mechanisms mentioned above.

\section{Conclusion}

The methanolic extract of Rumex vesicarius was proved as a natural safe remedy for the treatment of pyrexia in albino rabbit. Our current findings thus support the claims of traditional medicine practitioners as an antipyretic agent. It is also evident from the study that Rumex vesicarius exhibited dose dependent 
antipyretic action and their effects are almost parallel to the standard aspirin group at higher doses $(120,160$ $\mathrm{mg} / \mathrm{kg}$ body weight). However, further detail studies with purified fractions/bioactive compounds are required to know the exact mechanism of action of Rumex vesicarius leaves extract.

\section{Authors' contributions}

IAK and AA designed the study. HSS collected the research material and performed the whole bench work. SHM had given guidance during the study. ZM, AA and MAR drafted and revised the manuscript. All authors read and approved the final manuscript.

\section{Acknowledgements}

The authors are grateful to the Dean, Faculty of Pharmacy and the Vice Chancellor, Prof. Dr. Syed Khawaja Alqama, Bahauddin Zakariya University, Multan, Pakistan for providing the necessary facilities and fund to undertake this work.

\section{Competing interests}

The authors declare that they have no competing interests.

\section{References}

1. Semwal, D.K., Badoni, R., Semwal, R., Kothiyal, S.K., Singh, G.J.P. and Rawat, U. (2010) The genus Stephania (Menispermaceae): Chemical and pharmacological perspectives. J. Ethnopharmacol. 132:369-383.

2. Shinwari, Z.K. (2010) Medicinal plants research in Pakistan. J. Med. Plants Res. 4:161-176.

3. Saeed, M., Muhammad, N. and Khan, H. (2011) Assessment of heavy metal contents of branded Pakistani herbal products. Trop. J. Pharm. Res. 10(4):499-506.

4. Saeed, M., Muhammad, N. and Khan, H. (2010) Analysis of toxic heavy metals in branded Pakistani herbal products. $J$. Chem. Soc. Pak. 32(4):471-475.

5. Chattopadhyay, D., Ganeshan, A., Lopamudra, G., Rajendran, K., Asit, B.M. and Bhattacharya, S.K. (2005) Antipyretic activity of Alstonia macrophylla Wall ex A. DC: An ethnomedicine of Andaman Islands. J. Pharm. Pharm. Sci. 8:558-564.

6 Spacer, C.B. and Breder, C.D. (1994) The neurologic basis of fever. N. Engl. J. Med. 330:1880-1886.

7. Cheng, L.U.O., Ming-liang, H.E. and Lars, B. (2005) Reviw: Is COX-2 a perpetrator or a protector? Selective COX-2 inhibitors remain controversial. Acta Pharmacol. Sin. 26:
926-933.

8. Panduraju, T., Raja, S.R.P. and Sateesh, K.V. (2009) A study on antimicrobial activity of Rumex vesicarius Linn. Int. J. Pharm. Tech. 1(1):21-25.

9. Kirtikar, K.R. and Basu, B.D. (1980) Indian Medicinal Plants. International book distributors: Deradun, India. Vol. III, 2747.

10. Jebakumar, A.Z., Hassan, S.N., Siju, K.G. and Paramasivam, M. (2011) Anti-diarrhoeal activity of ethanolic extract of Rumex vesicarius seed. Int. J. Phytother. 1:6-10.

11. El-Hawary, S.A., Sokkar, N.M., Ali, Z.Y. and Yehia, M. (2011) A profile of bioactive compounds of Rumex vesicarius L. J. Food. Sci. 76(8):1195-1202.

12. Harborne, J.B. (1973) Methods of plant analysis. In: Phytochemical Methods. Champan and Hall, London. 1-7.

13. Grover, J.K. (1990) Experiments in Pharmacy and Pharmacology: CBS Publisher and Distributor, $1^{\text {st }}$ edition, Volume 2, Shahdara Delhi, India. 155.

14. Nammi, S., Boini, M.K., Lodagala, S.D. and Behara, R.B. (2003) The juice of fresh leaves of Catharanthus roseus Linn. reduce blood glucose in normal and alloxan diabetic rabbits. BMC Complement Alter. Med. 3:4-7.

15. Brithsh Veterinary Association Animal Welfare Foundation (BVAAWF), (1993) Fund for replacement of Animals in Medical Experiments (FRAME). Royal Society for the Prevention of Cruelty to Animal (RSPCA), Universities Federation for Animal Welfare (UFAW) Joint working group on Refinement. Refinement in rabbit husbandry. Lab Anim. 27:301-329.

16. Mutalik, S., Paridhavi, K., Rao, C.M. and Udupa, N. (2003) Antipyretic and analgesic effect of leaves of Solanum melongena Linn. in rodents. Indian J. Pharmacol. 35:312315.

17. Taran, S.G, Bezuglyi, P.A., Depeshko, I.T. and Golubenko, Y.A. (1984) Synthesis, structure, and biological activity of $\alpha$ acyl derivatives of N-R-oxamoylphenylhydrazines. Pharm. Chem. J. 18:17-20.

18. Mbagwu, H.O., Anene, R.A. and Adeyemi, O.O. (2007) Analgesic, antipyretic and antiinflammatory properties of Mezoneuron benthamianum Baill Caesalpiniaceae. Niger Quart. J. Hos. Med. 17(1):35-41.

19. Westfall, T.C. and Westfall, D.P. (2006) Adrenergic agonists and antagonists. In: Goodman \& Gilman's the pharmacological basis of therapeutics, $11^{\text {th }}$ Edition L.L. Brunton, J.S. Lazo, K.L. Parker), McGraw-Hill, New York. 237-295.

20. Chandrasekharan, N.V. (2002) COX-3, a cyclooxygenase-1 variant inhibited by acetaminophen and other analgesic/ antipyretic drugs: cloning, structure and expression. Proc. Nat.Acad.Sci. USA 99:13926-13931.

21. Rang, H.P. Dale, M.M, Ritter, J.M, Moore, P.K. (2007) Pharmacology, 6th Edition, Edinburgh, Churchill, Livingstone. 557-587. 